\title{
Review \\ Clinical review: Patient-ventilator interaction in chronic obstructive pulmonary disease
}

Philippe Jolliet ${ }^{1}$ and Didier Tassaux ${ }^{1,2}$

\author{
${ }^{1}$ Intensive Care, University Hospital, 1211 Geneva 14, Switzerland \\ ${ }^{2}$ Anesthesiology, University Hospital, 1211 Geneva 14, Switzerland
}

Corresponding author: Philippe Jolliet, jolliet@medecine.unige.ch

Published: 3 November 2006

This article is online at http://ccforum.com/content/10/6/236

(c) 2006 BioMed Central Ltd

\begin{abstract}
Mechanically ventilated patients with chronic obstructive pulmonary disease often prove challenging to the clinician due to the complex pathophysiology of the disease and the high risk of patientventilator asynchrony. These problems are encountered in both intubated patients and those ventilated with non-invasive ventilation. Much knowledge has been gained over the years in our understanding of the mechanisms underlying the difficult interaction between these patients and the machines used to provide them with the ventilatory support they often require for prolonged periods. This paper attempts to summarize the various key issues of patient-ventilator interaction during pressure support ventilation, the most often used partial ventilatory support mode, and to draw clinicians' attention to the need for sufficient knowledge when setting the ventilator at the bedside, given the often conflicting goals that must be met.
\end{abstract}

\section{Introduction}

In patients with chronic obstructive pulmonary disease (COPD), mechanical ventilation, both invasive (MV) and noninvasive (NIV), often proves challenging due to the interaction between the various pathophysiological mechanisms of the disease and the goals of ventilatory support $[1,2]$. Thanks to increased knowledge gained over the years, the severe complications associated with dynamic hyperinflation and intrinsic positive end-expiratory pressure (PEEPi) [3], first described over 20 years ago [4], have become less frequent $[2,3]$. However, some aspects of MV in these patients remain very difficult to manage, in particular patient-ventilator interaction, that is, the combination of the patient's spontaneous breathing activity and the ventilator's set parameters $[5,6]$. Further complicating the matter, during NIV, leaks at the patient-mask interface can interfere with various aspects of ventilator function, thereby increasing the risk of patient-ventilator asynchrony [7-10].
Overall, whereas the goal of ventilatory support is to provide some degree of unloading to the respiratory muscles, the opposite effect can occur if the patient and the ventilator engage in a tug-of-war between conflicting goals rather than sharing the respiratory workload, which can in turn lead to failure of NIV or the prolonged need for MV $[5,6]$.

The purpose of this paper is to review the basic mechanisms involved in patient-ventilator interaction in COPD patients, and to outline some of the possible paths towards improving this often difficult relationship.

\section{Basic mechanisms}

In a spontaneously breathing subject, the pressure generated by the respiratory muscles $\left(P_{\text {mus }}\right)$ during inspiration is dissipated to overcome both the elastic and resistive forces opposing respiratory system inflation, as described by the equation of motion of the respiratory system:

$$
P_{\text {mus }}=\left(R_{r s} \times V^{\prime}\right)+\left(E_{r s} \times V\right) \quad \text { (equation 1) }
$$

where $E_{r s}$ is respiratory system elastance, $R_{r s}$ is respiratory system resistance, $V^{\prime}$ is inspiratory flow, and $V$ is volume of the respiratory system above functional residual capacity.

During the controlled ventilation of a passive patient, $\mathrm{P}_{\text {mus }}=0$, and the necessary pressure is applied by the ventilator $\left(P_{a w}\right)$. Therefore, equation 1 becomes:

$$
P_{\mathrm{aw}}=\left(R_{\mathrm{rs}} \times \mathrm{V}^{\prime}\right)+\left(E_{\mathrm{rs}} \times \mathrm{V}\right) \quad \text { (equation 2) }
$$

In the case of assisted ventilatory modes, both the ventilator and the patient provide the required pressure, equation 1 becoming:

$\mathrm{COPD}=$ chronic obstructive pulmonary disease; $\mathrm{ET}=$ expiratory trigger; $\mathrm{ICU}=$ intensive care unit; $\mathrm{MV}=$ mechanical ventilation (invasive); $\mathrm{NAVA}=$ neurally adjusted ventilators assist; NIV = noninvasive ventilation; $P_{\text {alv }}=$ alveolar pressure; $P_{a o}=$ pressure present at the airway opening; $P_{\text {appl }}=$ total pressure applied to the respiratory system; $\mathrm{PAV}=$ proportional assist ventilation; $\mathrm{P}_{\mathrm{aw}}=$ pressure applied by the ventilator; $\mathrm{PEEP}=$ positive endexpiratory pressure; PEEPe = external PEEP; PEEPi = intrinsic PEEP; $P_{\text {mus }}=$ pressure generated by the respiratory muscles; $P S=$ pressure support; $\mathrm{TA}=$ trigger asynchrony $; \mathrm{V}_{\text {insp }}^{\prime}=$ instantaneous inspiratory flow; $\mathrm{V}_{\text {peak }}^{\prime}=$ peak inspiratory flow; $\mathrm{WOB}=$ work of breathing. 


$$
P_{\text {appl }}=P_{a w}+P_{\text {mus }}=\left(R_{r s} \times V^{\prime}\right)+\left(E_{r s} \times V\right) \quad \text { (equation 3) }
$$

where $\mathrm{P}_{\text {appl }}$ is total pressure applied to the respiratory system.

From equation 3 , one can easily see that, to maintain a constant $P_{\text {appl }}$, a change in any one of its determinants $\left(P_{\text {mus }}\right.$ or $\mathrm{P}_{\mathrm{aw}}$ ) must be met by an opposite change in the other.

In clinical terms, this means that, for instance, increasing the level of pressure support (PS) provided by the ventilator should lead to increased respiratory muscle unloading (decreased $P_{\text {mus }}$ ) [11]. However, changing the ventilator setting also affects the patient's breathing pattern through several mechanisms, such as a direct effect on neural drive [12], worsening of PEEPi, which in turn raises the inspiratory threshold load of triggering the ventilator [13], delayed expiratory cycling [14], and, during NIV, a higher risk of gastric air intake and leaks [10].

In the following paragraphs, we will examine the main aspects of these key determinants, following the time-course of a patient-triggered breath in pressure support [15], as it is the most commonly used partial ventilatory support mode [16]: triggering of the ventilator, pressurization slope and inspiratory flow, level of PS, and cycling (Figure 1). Although the discussion is centered on intubated patients, aspects specific to NIV will be outlined as well.

\section{Triggering of the ventilator}

Triggering refers to the mechanism by which a patient's inspiratory effort initiates a response from the ventilator, through either a decrease in the ventilator circuit pressure (pressure trigger), or the presence of an inspiratory flow (flow trigger). The main determinants affecting inspiratory muscle workload associated with triggering are the magnitude of change required and the delay between the onset of inspiratory effort and ventilator response. Initial studies comparing flow triggering and pressure triggering showed that the former entailed a lower work of breathing [17]. However, the difference is probably of little clinical relevance [18]. Furthermore, the latest generation intensive care unit (ICU) ventilators are equipped with very sensitive mechanisms, in terms of both the inspiratory effort required and initial delay, triggering thereby adding little to the overall work of breathing [19]. Nonetheless, on most machines the trigger sensitivity can be adjusted, and care should be taken to ensure that the highest possible sensitivity is set, without auto-triggering [20]. Of note, during NIV, leaks can be erroneously detected by the ventilator as an inspiratory effort, thereby triggering the ventilator. The frequency of this auto-triggering has been shown to correlate with the magnitude of the leak [7]. Of interest, many recent ventilators provide an 'NIV mode' designed to take leaks into account and adjust ventilator parameters, including triggering, accordingly.
Figure 1

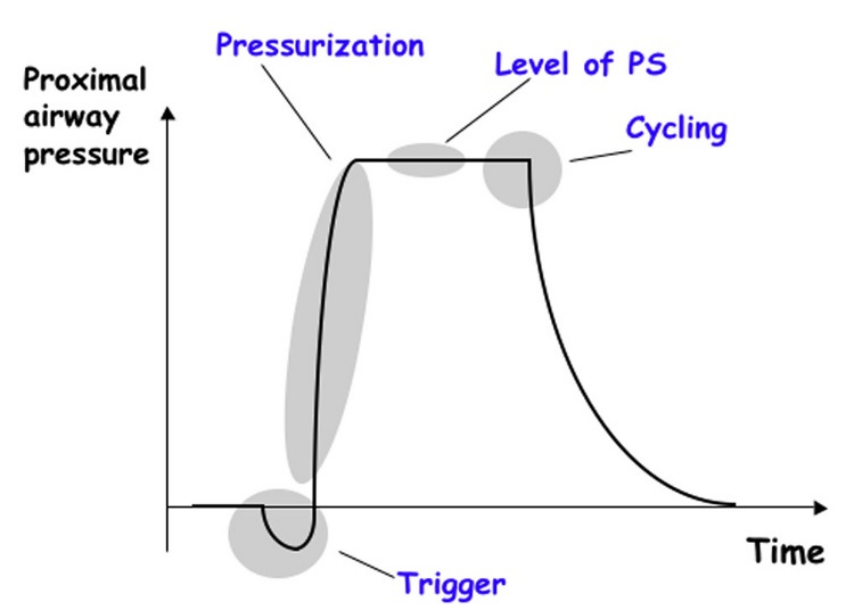

Schematic tracing of a pressure support (PS) cycle, highlighting its four key phases.

Despite the technical progress made, at least one major issue regarding triggering still persists; that of trigger asynchrony (TA) [21], which refers to the presence of inspiratory efforts that do not succeed in triggering the ventilator. The most common cause of such ineffective inspiratory attempts is the presence of PEEPi in COPD patients [21,22]. Indeed, for inspiratory flow to occur and trigger the ventilator, alveolar pressure $\left(P_{\text {alv }}\right)$ must decrease below the pressure present at the airway opening $\left(P_{a o}\right)$. In the presence of PEEPi, however, $P_{\text {alv }}$ must decrease by the additional amount of PEEPi. This added inspiratory threshold load often cannot be offset with each breath, the patient's respiratory rate therefore being higher than that reported by the ventilator. The combination of ineffective inspiratory efforts and added load even for triggering breaths can markedly increase the work of breathing (WOB) [22]. In this situation, even if the trigger sensitivity is set at its maximum, little improvement is obtained, since the offsetting of PEEPi is still necessary for the trigger to react [21]. Two options are available to reduce TA. One is to add external PEEP (PEEPe), which reduces the pressure difference between $P_{\text {alv }}$ and $P_{\text {ao }}$, and, therefore, the magnitude of $P_{\text {alv }}$ reduction required to generate an inspiratory flow. Applying PEEPe has been shown to decrease both the number of ineffective breaths and the WOB [22]. There is no validated approach to determine the optimal level of PEEPe. The pragmatic approach used in our ICU is to start at zero end-expiratory pressure (ZEEP), and to titrate PEEPe upwards by 1 to $2 \mathrm{cmH}_{2} \mathrm{O}$ increments, until ineffective inspiratory attempts markedly decrease or disappear.

The other option is to reduce the level of pressure support. Indeed, excessive levels of PS can result in the insufflation of a high tidal volume, which in turn can increase dynamic 
hyperinflation and PEEPi, thereby worsening TA. In this setting, reducing $P S$ has been shown to effectively decrease TA [13].

In recent years, new developments relying on microprocessor technology have attempted to further optimize triggering. One such approach, based on the analysis of the inspiratory flow waveform was shown to decrease the triggering effort in a small group of patients without COPD, at the price of some degree of instability in the form of autotriggering [23]. Another interesting technique is neurally adjusted ventilators assist (NAVA), which relies on the recording of the electromyographic activity of the diaphragm by means of a multi-electrode naso-gastric tube, and its immediate feedback to the ventilator to control the timing and level of ventilatory assist [24]. At this stage, clinical studies are needed to evaluate the potential for NAVA to improve patient-ventilator interaction and impact outcome.

\section{Pressurization slope and inspiratory flow}

During PS, the slope of pressurization, that is, the incremental increase in $P_{a w}$ per time unit, can be adjusted on most ventilators [19]. The steeper the slope, the faster $P_{a w}$ will rise to its target value. Studies performed in patients with obstructive mechanics have demonstrated that, compared to a slow pressurization rise time, a steep slope is associated with less WOB, and the steeper the slope the lower the WOB [25]. The same observation was made by Chiumello and colleagues [26], their results also showing that comfort was at its lowest at both the lowest and highest pressurization rates. During NIV, a study performed in COPD patients showed that the diaphragmatic pressure-time product was lower at the fastest pressurization rate, which was associated with a significant increase in air leaks and proved to be the most uncomfortable for the patients [9]. Therefore, it is probably wise not to decrease the PS rise time to $<100 \mathrm{~ms}$, and, if a patient exhibits discomfort, to increase the time up to $200 \mathrm{~ms}$.

\section{Level of pressure support}

As discussed in the first section of this review, in PS mode, one must take care to avoid both insufficient support leading to increased respiratory muscle load [27] and excessive support bearing the risk of worsening dynamic hyperinflation and PEEPi in obstructive patients [13] (Figure 2). Furthermore, recent data show that PS can also disrupt sleep through episodes of central apneas caused by hypocapnia [28]. A high level of PS can worsen the delayed cycling phenomenon as described in the next section. During NIV, leaks increase in proportion to the pressure generated inside the mask [10]. This last mechanism probably provides some safeguard against excessive tidal volume (VT) insufflation and gastric intake of air, but can lead to delayed cycling. Furthermore, given that ventilators differ markedly in their capacity to compensate for leaks [29], any increase in PS might paradoxically lead to a decrease in delivered VT due to
Figure 2

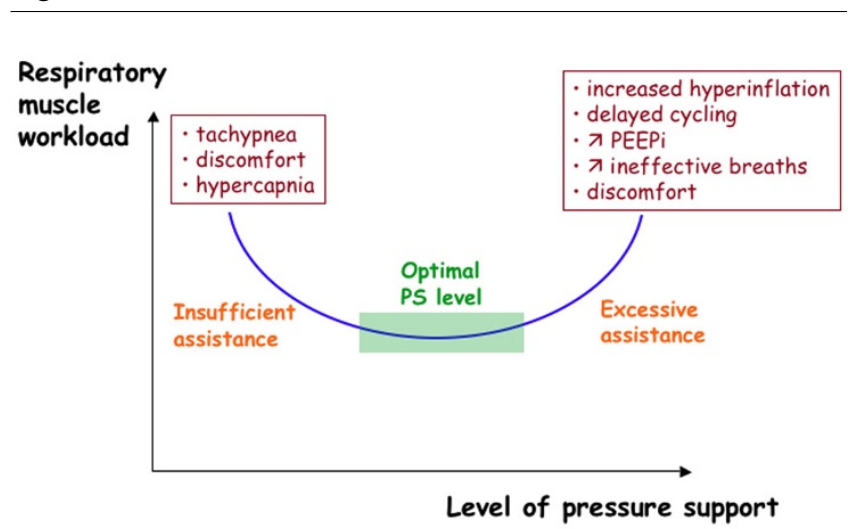

Conceptual diagram illustrating the adverse effects of both insufficient and excessive levels of pressure support (PS) on the respiratory muscle workload. PEEPi, intrinsic positive end-expiratory pressure.

the increase in leaks. Empirically, PS can be titrated on the expiratory tidal volume (approximately 8 to $10 \mathrm{ml} / \mathrm{kg}$, the lowest value being preferred in NIV) and the patient's respiratory rate, which should remain below 30/minute.

An innovative approach is to provide automatic titration of the level of PS, based on the continuous evaluation of respiratory rate, VT and end-tidal $\mathrm{CO}_{2}[30,31]$. Such a system was shown to improve parameters of patient-ventilator adaptation in a small group of intubated patients without COPD [31]. In a recent randomized multicenter study, in which $20 \%$ of patients had COPD, the system led to a decrease in the duration of weaning, total duration of MV including NIV, and to a shorter ICU stay compared to standard physician-driven weaning [32].

\section{Cycling}

In PS mode, the transition from inspiration to expiration, known as cycling, occurs when instantaneous inspiratory flow $\left(\mathrm{V}_{\text {insp }}^{\prime}\right)$ decreases to a predetermined fraction of peak inspiratory flow $\left(\mathrm{V}_{\text {insp }}^{\prime} / \mathrm{V}_{\text {peak }}^{\prime}\right)$, often referred to as an 'expiratory trigger' (ET) [15]. In an ideal situation, cycling coincides with the end of the patient's inspiratory effort. Prolonged pressurization by the machine into the patient's expiratory phase is known as delayed cycling. Delayed cycling can lead to expiratory asynchrony and increased WOB $[14,33]$. Delayed cycling has been shown to occur mostly in patients with obstructive airways disease [34-36]. On many ventilators, the cutoff value of ET is pre-determined, usually at a default setting of 0.25 ; that is, the ventilator cycles when $\mathrm{V}^{\prime}$ insp has decreased to $25 \%$ of $\mathrm{V}_{\text {peak. }}$. However, when airway resistance increases, the profile of the inspiratory flow curve changes, the curve spreading out and becoming flatter (Figure 3). Hence, the 0.25 point will be reached later, which in turn increases the likelihood of delayed cycling. The adverse consequences of delayed 
Figure 3

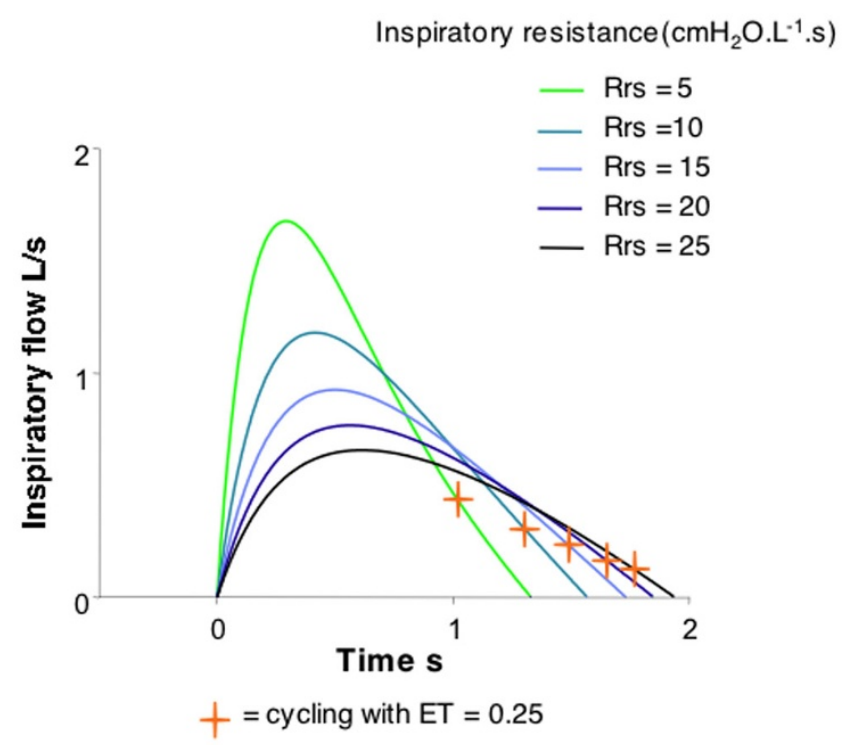

Mathematical modeling of the inspiratory instantaneous flow-time curve for progressively increasing levels of airway resistance (Rrs), from normal (5) to severe (20). The cross represents the point at which the inspiratory flow has decreased to $25 \%$ of its peak value, and corresponds to the default expiratory trigger (ET) on many ventilators.

cycling are summarized in Figure 4. Consequently, setting a higher value of ET should theoretically decrease the magnitude of delayed cycling [35], and thereby alleviate some of the adverse consequences outlined above (Figure 5). This hypothesis was tested in a recent study in which intubated COPD patients on PS were studied at various ET settings, ranging from 0.10 to 0.70 [37]. The study showed that at the higher ET values, the magnitude of delayed cycling was reduced, entailing as predicted a reduction in $\mathrm{PEEPi}$, ineffective inspiratory attempts and inspiratory muscle workload [37].

During NIV, additional factors can contribute to delayed cycling. Calderini and colleagues [8] showed that leaks around the mask led to a prolonged pressurization by the ventilator, in turn leading to an insufficient decrease in $\mathrm{V}^{\prime}{ }_{\text {insp }}$ to the cycling threshold. Consequently, cycling was considerably delayed, the patients were attempting to cycle the ventilator by active expiration [33] and WOB was increased [8]. The authors convincingly showed that relying on time rather than on flow cycling, that is, by limiting the maximum inspiratory time, delayed cycling, the magnitude of inspiratory efforts and WOB were all markedly reduced [8]. Naturally, reducing leaks can also contribute to alleviate this problem, but tight-fitting masks are a source of discomfort for patients, which can lead to overall intolerance to NIV and reduce its chances of success. Finally, delayed cycling can also occur as a result of increased leaks caused not by an insufficient mask seal but by a high pressurization rate [9].
Figure 4

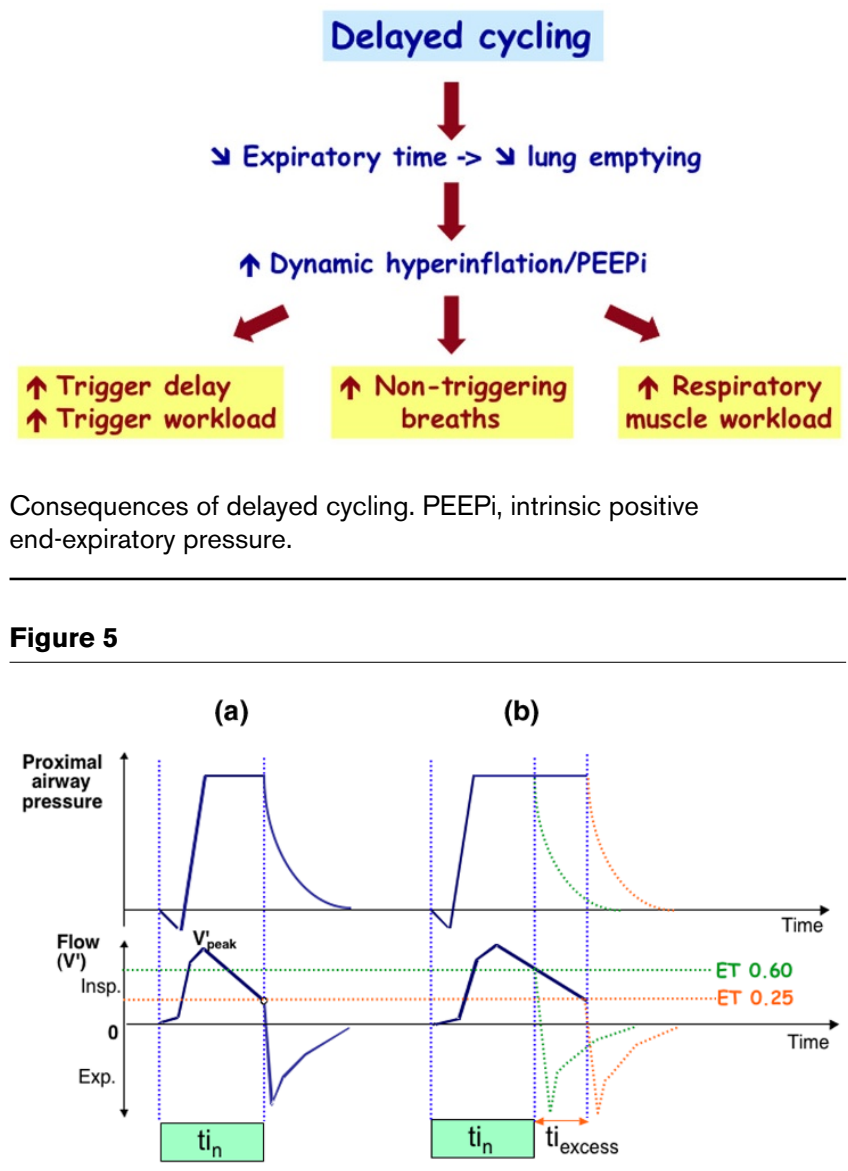

Airway and flow-time tracings illustrating the concept of delayed cycling. (a) Normal mechanics. The expiratory trigger (ET) setting is 0.25 . Cycling is ideal, that is, the inspiratory flow $\left(V^{\prime}\right)$ decreases to the 0.25 cycling level at the end of the patient's neural inspiration $\left(t_{n}\right)$. (b) Obstructive mechanics. The change in inspiratory flow curve derived from Figure 3 leads to the 0.25 level being reached later, well after the end of $\mathrm{ti}_{n}$. The magnitude of delayed cycling ( $\left(\mathrm{i}_{\text {excess }}\right)$ is illustrated by the double arrow. Increasing the level of ET to 0.6 of peak inspiratory flow corrects this problem, and cycling occurs once more at the end of $\mathrm{ti}_{\mathrm{n}}$. Exp., expiration; Insp., inspiration; $\mathrm{V}_{\text {peak }}$, peak inspiratory flow.

\section{Optimizing patient-ventilator synchrony with proportional assist ventilation}

Proportional assist ventilation (PAV) was developed in the early 1990 s and represents an innovative approach to respiratory muscle unloading $[38,39]$. Indeed, with $P S$, once the patient triggers the ventilator, $\mathrm{P}_{\mathrm{aw}}$ rises to a preset level, regardless of patient effort. Thus, PS provides a fixed level of inspiratory muscle unloading. PAV, on the other hand, amplifies patient effort without volume or pressure targets, its basic philosophy being that the more effort the patient develops to breathe, the more assistance is provided by the ventilator $[38,39]$. To achieve this goal, there are no conventional volume or pressure settings, as in other ventilatory 
modes. Rather, the physician sets a pressure gain applied by the machine on the patient's measured or estimated elastance and resistance. This allows for a compensation by the ventilator of an increase in either one or both of these components. Initial studies of PAV, centered on its pathophysiologcal effects, proved encouraging. PAV decreased WOB, increased VT and decreased peak $P_{\text {aw }}$ in intubated patients without COPD during weaning from mechanical ventilation [40,41]. In intubated COPD patients, PAV improved minute ventilation, decreased dyspnea, and reduced WOB [42], while preserving the physiological breath-by-breath VT variability better than PS [43]. Furthermore, in case of a sudden increase in mechanical load, PAV can maintain minute-volume and VT better than PS, and with less respiratory muscle load [44]. Despite these favorable effects, PAV can prove difficult to use in the clinical setting. Indeed, knowledge of the patients' elastance and resistance, a prerequisite for the correct titration of their compensation by PAV, is most often unavailable to the clinician [45]. Therefore, arbitrary levels of compensation are often used, which, if inappropriately chosen, can increase inspiratory effort in some patients [46]. Furthermore, although theoretically PAV should provide optimal cycling characteristics $[38,39]$, some doubts have recently been cast on this assumption [47]. In summary, although PAV has been developed more than a decade ago, its routine clinical implementation has so far not been achieved on a widespread scale, most likely because of its relative complexity and instability, presently positioning it more as a valuable tool to explore the regulation of ventilation than as an everyday ventilatory mode $[45,48]$.

\section{Conclusion}

Over the past 15 years, considerable knowledge has been gained in our understanding of the extremely complex issue of patient-ventilator interaction in COPD patients. Given the increasing use of assisted modes, this heightened understanding has become crucial in the everyday clinical management of mechanically ventilated patients. The various key phases and pitfalls of a ventilator-assisted breath should be understood by ICU physicians and caregivers to reduce unnecessary respiratory muscle workload and improve patient comfort. Special attention should be paid to patients undergoing NIV in whom leaks compound those problems encountered in intubated patients. New approaches such as closed-loop modes are beginning to prove their efficacy during key periods, such as weaning, as they have the potential for making numerous on-line adjustments to the patient's ventilatory demand.

\section{Competing interests}

PJ has received financial support for research projects from ResMed and Draeger but received no financial support for the present paper.

\section{References}

1. Gladwin M, Pierson D: Mechanical ventilation of the patient with severe chronic obstructive pulmonary disease. Intensive Care Med 1998, 24:898-910.

2. Sethi J, Siegel M: Mechanical ventilation in chronic obstructive lung disease. Clin Chest Med 2000, 21:799-818.

3. Rossi A, Polese G, Brandi G, Conti G: Intrinsic positive endexpiratory pressure. Intensive Care Med 1995, 21:522-536.

4. Pepe, $\mathrm{P}$ Marini J: Occult positive end-expiratory pressure in mechanically ventilated patients with airflow obstruction. $A m$ Rev Respir Dis 1982, 126:166-170.

5. Tobin MJ, Jubran A, Laghi F: Patient-ventilator interaction. $A m \mathrm{~J}$ Respir Crit Care Med 2001, 163:1059-1063.

6. Kondili E, Prinianakis G, Georgopoulos D: Patient-ventilator interaction. $\mathrm{Br} J$ Anaesth 2003, 91:106-119.

7. Bernstein G, Knodel E, Heldt G: Airway leak size in neonates and autocycling of three flow-triggered ventilators. Crit Care Med 1995, 23:1739-1744.

8. Calderini E, Confalonieri M, Puccio P, Francavilla N, Stella L, Gregoretti $\mathrm{C}$ : Patient-ventilator asynchrony during noninvasive ventilation: the role of expiratory trigger. Intensive Care Med 1999, 25:662-667.

9. Prinianakis G, Delmastro M, Carlucci A, Ceriana P, Nava S: Effect of varying the pressurisation rate during noninvasive pressure support ventilation. Eur Respir J 2004, 23:314-320.

10. Schettino GP, Tucci MR, Sousa R, Valente Barbas CS, Passos Amato MB, Carvalho CR: Mask mechanics and leak dynamics during noninvasive pressure support ventilation: a bench study. Intensive Care Med 2001, 27:1887-1891.

11. Brochard L, Harf A, Lorino H, Lemaire F: Inspiratory pressure support prevents diaphragmatic fatigue during weaning from mechanical ventilation. Am Rev Respir Dis 1989, 139:513-521.

12. Georgopoulos D, Roussos C: Control of breathing in mechanically ventilated patients. Eur Respir J 1996, 9:2151-2160.

13. Leung $P$, Jubran $A$, Tobin $M$ : Comparison of assisted ventilator modes on triggering, patient effort, and dyspnea. Am J Respir Crit Care Med 1997, 155:1940-1948.

14. Jubran A, Van de Graaf W, Tobin M: Variability of patient-ventilator interactions with pressure support ventilation in patients with chronic obstructive pulmonary disease. Am J Respir Crit Care Med 1995, 152:129-136.

15. Brochard L: Inspiratory pressure support. Eur J Anesthesiol 1994, 11:29-36.

16. Esteban A, Anzueto A, Alia I, Gordo F, Apezteguia C, Palizas F, Cide D, Goldwaser R, Soto L, Bugedo G, et al:: How is mechanical ventilation employed in the intensive care unit? An international utilization review. Am J Respir Crit Care Med 2000, 161:1450-1458

17. Aslanian $P, E l$ Atrous S, Isabey D, Valente E, Corsi D, Harf A, Lemaire $F$, Brochard L: Effects of flow triggering on breathing effort during partial ventilatory support. Am J Respir Crit Care Med 1998, 157:135-143.

18. Tütüncu A, Cakar N, Camci E, Esen F, Telci L, Akpir K: Comparison of pressure- and flow-triggered pressure-support ventilation on weaning parameters in patients recovering from acute respiratory failure. Crit Care Med 1997, 25:756-760.

19. Richard JC, Carlucci A, Breton L, Langlais N, Jaber S, Maggiore $S$, Fougere S, Harf A, Brochard L: Bench testing of pressure support ventilation with three different generations of ventilators. Intensive Care Med 2002, 28:1049-1057.

20. Hill LL, Pearl R: Flow triggering, pressure triggering, and autotriggering during mechanical ventilation. Crit Care Med 2000, 28:579-581.

21. Chao D, Scheinhorn D, Stearn-Hassenpflug M: Patient-ventilator trigger asynchrony in prolonged mechanical ventilation. Chest 1997, 112:1592-1599.

22. Nava S, Bruschi C, Rubini F, Palo A, lotti G, Braschi A: Respiratory response and inspiratory effort during pressure support ventilation in COPD patients. Intensive Care Med 1995, 21: 871-879.

23. Prinianakis G, Kondili E, Georgopoulos D: Effects of the flow waveform method of triggering and cycling on patient-ventilator interaction during pressure support. Intensive Care Med 2003, 29:1950-1959.

24. Sinderby C, Navalesi P, Beck J, Skrobik Y, Comtois N, Friberg S, Gottfried SB, Lindstrom L: Neural control of mechanical ventilation in respiratory failure. Nat Med 1999, 5:1433-1436. 
25. Bonmarchand G, Chevron V, Chopin C, Jusserand D, Girault C, Moritz $F$, Leroy J, Pasquis $P$ : Increased initial flow rate reduces inspiratory work of breathing during pressure support ventilation in patients with exacerbation of chronic obstructive pulmonary disease. Intensive Care Med 1996, 22: 1147-1154.

26. Chiumello D, Pelosi P, Croci M, Bigatello L, Gattinoni L: The effects of pressurization rate on breathing pattern, work of breathing, gas exchange and patient comfort in pressure support ventilation. Eur Repsir J 2001, 18:107-114.

27. Appendini L, Purro A, Patessio A, Zanaboni S, Carone M, Spada $E$, Donner C, Rossi A: Partitioning of inspiratory muscle workload and pressure assistance in ventilator-dependent COPD patients. Am J Respir Crit Care Med 1996, 154:1301-1309.

28. Parthasarathy S, Tobin MJ: Effect of ventilator mode on sleep quality in critically ill patients. Am J Respir Crit Care Med 2002, 166:1423-1429.

29. Mehta S, McCool F, Hill NS: Leak compensation in positive pressure ventilators: a lung model study. Eur Respir J 2001, 17:259-267.

30. Dojat M, Harf A, Touchard D, Laforest M, Lemaire F, Brochard L: Evaluation of a knowledge-based system providing ventilatory management and decision for extubation. Am J Respir Crit Care Med 1996, 153:997-1004.

31. Dojat M, Harf A, Touchard D, Lemaire F, Brochard L: Clinical evaluation of a computer-controlled pressure support mode. Am J Respir Crit Care Med 2000, 161:1161-1166.

32. Lellouche F, Mancebo J, Jolliet P, Roeseler J, Schortgen F, Dojat M, Cabello M, Bouadma L, Rodriguez P, Maggiore S, Reynaert M, Merssmann S, Brochard L: A multicenter randomized trial of computer-driven protocolized weaning from mechanical ventilation. Am J Crit Care Respir Med 2000, 174:894-900.

33. Parthasarathy S, Jubran A, Tobin M: Cycling of inspiratory and expiratory muscle groups with the ventilator in airflow limitation. Am J Respir Crit Care Med 1998, 158:1471-1478.

34. Nava S, Bruschi C, Fracchia C, Braschi A, Rubini F: Patient-ventilator interaction and inspiratory effort during pressure support ventilation in patients with different pathologies. Eur Respir J 1997, 10:177-183.

35. Tassaux D, Michotte J, Gainnier M, Gratadour P, Fonseca S, Jolliet $P$ : Expiratory trigger setting in pressure support ventilation: from mathematical model to bedside. Crit Care Med 2004, 32: 1844-1850.

36. Tokioka $H$, Tanaka $T$, Ishizu $T$, Fukushima $T$, Iwaki T, Nakamura $Y$, Kosogabe $Y$ : The effect of breath termination criterion on breathing patterns and the work of breathing during pressure support ventilation. Anesth Analg 2001, 92:161-165.

37. Tassaux D, Gainnier M, Battisti A, Jolliet P: Impact of expiratory trigger setting on delayed cycling and inspiratory muscle workload. Am J Respir Crit Care Med 2005, 172:1283-1289.

38. Younes M: Proportional assist ventilation, a new approach to ventilatory support. Part 1: Theory. Am Rev Respir Dis 1992, 145:114-120.

39. Younes M: Proportional assist ventilation. In Principles and Practice of Mechanical Ventilation. Edited by Tobin M. New York: McGraw Hill; 1994:349-369.

40. Younes M, Puddy A, Roberts D, Light RB, Quesada A, Taylor K, Oppenheimer $\mathrm{L}$, Cramp $\mathrm{H}$ : Proportional assist ventilation. Results of an initial clinical trial. Am Rev Respir Dis 1992, 145: 121-129.

41. Navalesi P, Hernandez P, Wongsa A, Laporta D, Goldberg P, Gottfried SB: Proportional assist ventilation in acute respiratory failure: effects on breathing pattern and inspiratory effort. $A m$ J Respir Crit Care Med 1996, 154:1330-1338.

42. Ranieri VM, Grasso S, Mascia L, Martino S, Fiore T, Brienza A, Giuliani R: Effects of proportional assist ventilation on inspiratory muscle effort in patients with chronic obstructive pulmonary disease and acute respiratory failure. Anesthesiology 1997, 86:79-91.

43. Wrigge $\mathrm{H}$, Golisch $\mathrm{W}$, Zinserling J, Sydow M, Almeling G, Burchardi $H$ : Proportional assist versus presure support venilation: effects on breathing pattern and respiratory work of patients with chronic obstructive pulmonary disease. Intensive Care Med 1999, 25:790-798.

44. Grasso S, Puntillo F, Mascia L, Ancona G, Fiore T, Bruno F, Slutsky AS, Ranieri VM: Compensation for increase in respiratory workload during mechanical ventilation. Pressure- support versus proportional-assist ventilation. $A m$ J Respir Crit Care Med 2000, 161:819-826.

45. Ambrosino N, Rossi A: Proportional assist ventilation (PAV): a significant advance or a futile struggle between logic and practice? Thorax 2002, 57:272-276.

46. Delaere S, Roeseler J, D'Hoore $W$, Matte P, Reynaert M, Jolliet $P$, Sottiaux T, Liistro G: Respiratory muscle workload in intubated, spontaneously breathing patients without COPD: pressure support vs. proportional assist ventilation. Intensive Care Med 2003, 29:949-954.

47. Du H, Ohtsuji M, Shigeta M, Chao D, Sasaki K, Usuda Y, Yamada $\mathrm{Y}$ : Expiratory asynchrony in proportional assist ventilation. $\mathrm{Am}$ $J$ Respir Crit Care Med 2002, 165:972-977.

48. Vitacca $M$ : New things are not always better: proportional assist ventilation vs. pressure support ventilation. Intensive Care Med 2003, 29:1038-1040. 